\title{
The pulmonary cachexia syndrome: aspects of energy balance
}

\author{
Jo Congleton \\ Respiratory Medicine Division, Hammersmith Hospital, Du Cane Road, London W12, UK
}

\begin{abstract}
The present paper reviews current knowledge of the pulmonary cachexia syndrome with reference to chronic obstructive pulmonary disease (COPD). Aspects of incidence, aetiology and management are discussed. Malnutrition occurs in approximately one-quarter to one-third of patients with moderate to severe COPD. Both fat mass and fat-free mass become depleted. Loss of fat-free mass is the more important and appears to be due to a depression of protein synthesis. Weight loss is an independent prognostic indicator of mortality, and is associated with increased morbidity and decreased health-related quality of life. The aetiology of malnutrition in COPD is not well understood. Reduced food intake does not seem to be the primary cause. Resting energy expenditure (REE) is elevated in a proportion of patients and probably contributes to negative energy balance. Measurement of actual REE is helpful when considering the adequacy of nutritional supplementation. The underlying reason for a hypermetabolic state is not known. Although weight-losing COPD patients are not catabolic, nutritional supplementation alone does not appear to reverse the loss of fat-free mass. Strategies involving nutritional supplementation in combination with a second intervention are being explored, and there are some encouraging results using anabolic hormones.
\end{abstract}

Pulmonary cachexia syndrome: Chronic obstructive pulmonary disease: Energy balance: Body-weight loss: Malnutrition

Malnutrition is a feature of lung cancer as in many other cancers, but it is also a feature of lung disease of a non-malignant aetiology and then has been termed 'the pulmonary cachexia syndrome'. Weight loss may be very marked and difficult to reverse, in addition the aetiology is not well understood. The following article is a review of current knowledge. The majority of information comes from work with chronic obstructive pulmonary disease (COPD) and the present article will focus on malnutrition in this condition, noting that malnutrition may be seen also in other end-stage lung diseases such as cystic fibrosis and interstitial lung disease.

\section{Incidence and pattern of malnutrition}

COPD is characterized by progressive irreversible airflow obstruction, fibrosis and distortion of the small airways, and destruction of the alveolar-pulmonary capillary interface (emphysema). Aetiology is tightly linked to past or present cigarette smoking. The forced expiratory volume in $1 \mathrm{~s}$ is the best indicator of the degree of airflow obstruction and is also the best predictor of life expectancy. Typically, symptoms of exertional breathlessness develop at age 50-60 years and progress with time, sometimes to the point where breathlessness occurs on the most minimal of activities, such as washing. Weight loss has been recognized to be a feature of COPD for many years. Using criteria of loss of 5-10\% initial body weight, or weight less than $90 \%$ ideal body weight (IBW), the reported incidence of malnutrition is between 24 and $35 \%$ of patients with moderate to severe COPD. Early studies tended to report data on either hospital inpatients or other highly-selective patient groups. However, Wilson et al. (1989) reported that $24 \%$ of 779 men with COPD recruited for a large US national outpatient trial had a body weight less than $90 \%$ IBW. More recently, Schols et al. (1993) studied 255 consecutive patients of both sexes admitted for intensive pulmonary rehabilitation in The Netherlands. Mean forced expiratory volume in $1 \mathrm{~s}$ was approximately $35 \%$ predicted value, mean age 64 years, and in this group $35 \%$ weighed less than $90 \%$ IBW. A similar prevalence was recorded in the UK, in sixty-nine outpatients with moderate to severe COPD (mean forced expiratory volume in $1 \mathrm{~s} 35 \%$ predicted value), $36 \%$ weighed less than $90 \%$ IBW (Congleton, 1998).

\footnotetext{
Abbreviations: COPD, chronic obstructive pulmonary disease; DIT, diet-induced thermogenesis; IBW, ideal body weight; REE, resting energy expenditure. Corresponding author: Dr Jo Congleton, present address Worthing General Hospital, Lyndhurst Road, Worthing BN11 2HR, UK, fax +44 (0) 1903285045 , email101503.1514@compuserve.com
} 
Studies of body composition in COPD show that both fat mass and fat-free mass are lost. Although some early studies placed importance on loss of fat mass, more recent work has indicated that depletion of fat-free mass may be more important. Hunter et al. (1981) carried out a detailed nutritional assessment of thirty-eight patients with COPD of varying degrees of severity. This group found marked depletion of both subcutaneous fat stores and muscle mass, and that the pattern met the criteria of protein-energy malnutrition. Schols et al. (1993) showed that depletion of fat-free mass could occur in patients apparently maintaining weight, and that it was depletion of fat-free mass that was important functionally. The results of studies of leg and whole-body amino acid and protein flux have suggested that the mode of muscle protein depletion in COPD is by a reduction of muscle synthesis rather than an increase in muscle breakdown (Morrison et al. 1988). This is a similar mechanism to muscle wasting in cancer cachexia, thyrotoxicosis and muscular dystrophy, but contrasts with cardiac cachexia in which there is increased muscle breakdown in addition to reduced synthesis. There are several possible mechanisms which could lead to depressed muscle protein synthesis. Induced hypoxia depresses protein synthesis in experimental conditions, possibly because cellular hypoxia reduces the ATP production necessary for muscle protein synthesis (Rennie et al. 1983). However, the typical clinical picture is of a wasted emphysematous patient with approximately normal arterial blood gases (a 'pink puffer'), and a hypoxaemic overweight 'blue bloater'. A strong correlation between low arterial partial pressure of $\mathrm{O}_{2}$ and muscle wasting in COPD has not been reported in the literature. Chronic malnutrition itself may contribute to depressed protein synthesis (Holt et al. 1963), and immobility leads to both disuse atrophy (Sargeant et al. 1977), and depression of muscle protein synthesis (Gibson et al. 1987). Corticosteroid therapy is known to depress the rate of protein synthesis and cause a true myopathy, and thus may exacerbate muscle depletion, but severe muscle wasting is seen in patients not taking corticosteroids. Visceral protein appears to be maintained, since circulating levels of serum proteins such as transferrin and albumin are not generally depressed. There is no evidence of vitamin deficency being important in this group of patients (Driver et al. 1982), although interest in the role of vitamins and antioxidant-oxidant balance in respiratory disease is increasing.

\section{Mortality and morbidity}

Weight loss may be only a marker of disease progression in COPD (i.e. a marker of worsening of airflow limitation), but there are several theoretical ways in which malnutrition might independently interact with disease state. Reduced respiratory muscle strength, reduced ventilatory response to hypoxia, poor wound healing and decreased cell-mediated immunity could all compromise a patient with poor respiratory function and increase the risk of deterioration. An acute exacerbation of COPD is itself associated with weight loss, leading to further worsening of nutritional status (Wilson et al. 1985). Early work supported the clinical impression that weight loss was associated with a poor prognosis. In the retrospective study of Sukumalchantra \&
Williams (1965), mortality was five of twelve in the group with weight loss and five of thirty-two in the group without weight loss $(P=0.08)$. Vandenbergh et al. (1967) found an increased mortality in a group of seventy-one patients with weight loss greater than $10 \%$. The weight-losing group and non-weight-losing groups were selected differently for the follow-up period in this study, and in an attempt to compare prognoses, a subset were chosen who were comparable and were followed-up for a further period. Survival was better in the group without weight loss, 5-year survival being $76 \%$ v. $49 \%$ despite similar mean initial weight. It has been suggested that low body weight is merely a surrogate marker for severely-impaired lung function. Wilson et al. (1989) retrospectively examined data from 779 men collected over 3 years and found that weight loss was a prognostic factor independent of forced expiratory volume in $1 \mathrm{~s}$. This finding was particularly marked in the group of patients with better lung function.

Potentially, wasting of the respiratory muscles could be of great importance, as respiratory muscle fatigue and weakness could predispose to respiratory failure and further increase energy requirements. Muscle contains a mixture of type 1 fibres (slow-twitch, $\mathrm{O}_{2}$-dependent, fatigue-resistant) and type 2 fibres (fast-twitch, mainly dependent on glycolytic stores). Slow-twitch fibres are recruited during lowintensity contractions. As the intensity of contraction increases, fast-twitch fatigue-resistant, and later fast-twitch fatiguable fibres, are recruited. In rats the effect of undernutrition has been shown to be greater on fast-twitch (type 2) fibres than on slow-twitch (type 1) fibres (Lewis et al. 1987). Thurlbeck's (1978) study on diaphragm weight implies that respiratory muscle wasting may be an important effect of malnutrition. This post-mortem study of 184 emphysematous patients found that diaphragm weight was lower than expected for body weight, probably because respiratory muscle consists of a higher proportion of type 2 fibres than peripheral muscle and these are relatively more affected by undernutrition than type 1 fibres. Arora \& Rochester (1982) showed that severe malnutrition greatly reduced respiratory muscle strength in non-respiratory patients, but in this study thirteen of the sixteen subjects had malignancy and therefore a paraneoplastic process may have been operating. Studies of respiratory muscle strength and malnutrition in COPD have given conflicting results. Some groups have shown reduction in inspiratory and expiratory muscle strength in underweight patients (Donahoe et al. 1989; Gray-Donald et al. 1989; Schols et al. 1991a). However, other groups have shown that body weight makes only a small contribution to respiratory muscle strength, which is more affected by the degree of mechanical disadvantage of the respiratory muscles due to hyperinflation (Lewis et al. 1986; Knowles et al. 1988). However, peripheral skeletal muscles do seem to be functionally affected. Efthimiou et al. (1988) showed a significantly reduced handgrip strength in underweight COPD patients compared with normal-weight COPD patients. Schols et al. (1991a) assessed 12 min walking distance in fifty-four patients with severe airflow obstruction, and although there was a strong correlation between \% IBW and walking distance ( $r 0.61)$, there was a better correlation between fat-free mass and walking distance. This latter correlation was particularly 
marked in underweight patients, and contrasts with the lack of correlation between airflow obstruction and walking distance in this study.

An increased susceptibility to certain types of infection, probably due to decreased cell-mediated immunity, is a feature of malnutrition in other conditions (Chandra, 1980). This is potentially important in COPD where a relatively minor infection could compromise respiratory function greatly. Cell-mediated immunity can be assessed by skinprick tests for cutaneous delayed hypersensitivity, which evaluates the T-cell memory response and is usually depressed in protein-energy malnutrition (Chandra, 1980). In addition, there is a reduction in the number of circulating $\mathrm{T}$ lymphocytes, and in vitro lymphocyte response to mitogens and antigens is also reduced. There have been conflicting results in studies assessing cell-mediated immunity in COPD. Hunter et al. (1981) found negative skin-prick tests in approximately one-third of thirty-eight COPD patients with varying disease severity, although the total lymphocyte count was elevated, which is normally associated with a preserved cellular immune function. Similarly, Gray-Donald et al. (1989) reported no difference in total lymphocyte count between underweight and normal-weight patients. Driver et al. (1982) found a high incidence of skin anergy in a group of malnourished COPD patients with respiratory failure and, in contrast to the previously described studies, that total lymphocyte count was reduced compared with that of the better-nourished non-respiratory-failure group. However, Wilson et al. (1986) found intact delayed hypersensitivity in all six severely-malnourished patients in a feeding study (weight $62-81 \%$ IBW). An increased incidence of infections in underweight COPD patients has not been shown, and it appears on balance that the integrity of immune function in this group is preserved.

It is possible that low body weight is a factor in the lethargy and exhaustion patients feel. Wilson et al. (1989) reported that there was no association between \% IBW and the physical score of the sickness-impact profile in 779 male COPD patients. However, our group found a strong relationship between quality of life and malnutrition, with low fatfree mass being particularly associated with a poor 'activity' score in the St George's Hospital respiratory questionnaire (Jones et al. 1992), and low fat mass being associated with a poor 'impact' score (Congleton \& Muers, 1995).

\section{Aetiology of malnutrition in COPD}

Weight loss occurs when energy expenditure exceeds energy intake, i.e. there is negative energy balance. Negative balance occurs in exacerbations of COPD due to an increased energy requirement and decreased intake. This stepwise fall in weight associated with exacerbations has been proposed to account for weight loss in COPD (Wilson et al. 1985). The steady chronic loss which occurs despite a stable clinical state may be at least as, or more, important. Negative energy balance may be caused by reduced intake, reduced absorption, inefficient fuel uptake, and increased energy expenditure. These factors may occur in isolation or in combination, and evidence for each factor is now reviewed.

\section{Reduced intake?}

Reduced energy intake was initially assumed to be an important factor, and there are many reasons why it may occur in these patients. Dyspnoea could increase due to irregular breathing while eating and swallowing, or due to gastric filling reducing functional residual capacity. It has been suggested that patients with COPD may eat suboptimally because chewing and swallowing alter the breathing pattern and cause arterial $\mathrm{O}_{2}$ desaturation (Schols et al. 1991b). Interpretation of food-intake studies is difficult, since dietary intake is notoriously difficult to assess. Another problem is that intake is often compared with the predicted energy requirement, which may underestimate the true requirement for attaining energy balance. Schols et al. (1991b) studied arterial $\mathrm{O}_{2}$ desaturation during eating in forty-four patients. Overall the $\mathrm{O}_{2}$ saturation fell by a very small degree within 5 min of commencing eating and rose a few minutes after completion of the meal. Saturation at $30 \mathrm{~min}$ was still slightly lower than at baseline $(85.3 \% \mathrm{v}$. $87.5 \%$ ). There was no difference in desaturation, transcutaneous partial pressure of $\mathrm{CO}_{2}$ and heart-rate response between the weight losers and non-weight losers. However, when the twenty hypoxaemic patients were subdivided into those for whom desaturation was $>4 \%$ when eating and those for whom desaturation was $<4 \%$, the group with desaturation $>4 \%$ were found to be more dyspnoeic and weigh significantly less $(54.9 \mathrm{~kg} v .74 .7 \mathrm{~kg})$. Any arterial $\mathrm{O}_{2}$ desaturation that does occur is not metabolic in origin, since the onset after commencing eating is quick and nasogastric administration of food does not cause $\mathrm{O}_{2}$ desaturation, (Brandstetter et al. 1988). In a different study of eighty pulmonary rehabilitation patients, Schols et al. (1991c) found a lower dietary intake in the hypoxaemic group compared with a non-hypoxaemic group. Hypoxia-related appetite suppression has been suggested as a cause of undernutrition in COPD, as it has been noted that appetite suppression, particularly for fatty foods, occurs at extreme altitude (Pugh, 1962), but this hypothesis has not been tested further. Studies of food intake have been informative. Hunter et al. (1981) found energy intake in a group of thirtyeight patients with COPD of varying severity was greater than the recommended daily amount at $10.6 \mathrm{MJ}(2535 \mathrm{kcal})$, both in weight losers and non-weight losers. Braun et al. (1984) found that energy intake was inversely correlated with \% IBW in sixty consecutive outpatients, suggesting that there is an attempt to compensate for weight loss. However, Schols et al. (1991c) found that mean dietary intake of energy when expressed as a percentage of actual measured resting energy expenditure (REE) was significantly less in weight losers than in weight-stable patients, although both values were over $100 \%(119 \%$ v. $134 \%, P<0.05)$. Measured REE was greater than theoretical REE in both groups (117\% and $108 \%$ respectively), and this highlights the importance of measuring REE in this group of patients when assessing whether intake is adequate. The findings of previously mentioned studies suggest that decreased intake is not the primary underlying cause of weight loss, although intake may not match requirements when weight loss is occurring, thus exacerbating the situation. This finding might account for the general failure of 
studies of supplemental feeding to show prolonged weight gain in COPD patients.

\section{Reduced absorption?}

Malabsorption does not seem to be an important factor. Semple et al. (1979) carried out detailed malabsorption studies on eight severely-underweight COPD patients, including jejunal biopsy, faecal fat estimation, D-xylose excretion, Fe, vitamin $\mathrm{B}_{12}$ and folate estimation, with normal results for all measurements.

\section{Abnormal handling of nutrients or inefficient fuel uptake?}

The physiological response to semistarvation is for REE to fall and to be associated with a progressive increase in utilization of fat for energy and conservation of $\mathrm{N}$. In conditions such as sepsis or acute injury there is an increase in REE associated with reduced carbohydrate oxidation and increased fat and protein oxidation. It is important to note that unlike other weight-losing patients, e.g. those with severe burns or sepsis, COPD patients are not catabolic (Goldstein et al. 1988). This situation has implications when considering intervention as, theoretically, adequate energy intake should lead to an increase in weight at a rate similar to that of other depleted patients. Goldstein et al. (1988) reported that malnourished individuals with lung disease have a pattern of energy metabolism that is distinctly different from that of malnourished individuals without lung disease (surgical and anorexic patients), with increased carbohydrate and protein oxidation, and no preferential fat oxidation occurring in the COPD group. However, subsequent studies have reported differing results. Green \& Muers (1991) studied ten COPD patients and six controls and found that there was an increase in fasting fat oxidation in the COPD group. Substrate balance calculations showed that the COPD patients stored less protein as a proportion of intake after a meal, and this would exacerbate muscle wasting.

\section{Increased energy expenditure?}

There are three main components to total energy expenditure: diet-induced thermogenesis (DIT), activity-related thermogenesis, and REE. The major component is REE, accounting for between $60 \%$ and $80 \%$ of the total, depending on the level of general activity and the fuel mix. DIT accounts for approximately $10 \%$ of the total and activityrelated thermogenesis accounts for little, particularly in a relatively sedentary group.

Increased diet-induced thermogenesis? Studies on DIT report differing results and different interpretations of the data. These differences may be due partly to the different test feeds used, different ways of expressing DIT and different types of subjects acting as controls. Goldstein et al. (1987) compared DIT in ten malnourished COPD patients with five malnourished non-respiratory patients using both a fat-based and a carbohydrate-based refeeding regimen. The energy intake consisted of 1.7 times the basal REE, which was significantly greater in the COPD group. During the fatbased regimen the average daily energy expenditure rose from $90 \%$ to $98 \%$ of the value predicted by the Harris-
Benedict (Harris \& Benedict, 1919) equation in the control group and from $116 \%$ to $130 \%$ of the predicted value in the COPD group (i.e. rose by $9 \%$ and $12 \%$ respectively). With the carbohydrate-based regimen REE rose to $99 \%$ and $136 \%$ of the predicted value respectively (i.e. by $10 \%$ and $17 \%$ respectively). Since (1) these values are given as a percentage of the predicted values, (2) the energy intake of the two groups was different, and (3) the 'control' group were malnourished, it is difficult to decide whether this finding represents a true increase in DIT. In fact, Hugli et al. (1993) recalculated the data and reported that on the carbohydrate-based regimen DIT was $15 \%$ of the baseline value in the COPD group v. $18 \%$ in controls and on the fat-based regimen was $11 \%$ v. $13 \%$ respectively, both differences were non-significant. Green \& Muers (1991) studied ten emphysematous patients and six healthy controls, and measured DIT following a protein-rich meal standardized to body weight. DIT was expressed as a percentage of energy intake and was found to be increased in patients compared with controls. However, the same group reported different results in a subsequent paper (Green \& Muers, 1992), although the study conditions were different. They found that DIT and both pre- and postprandial fuel mix were similar in emphysematous COPD patients, bronchitic COPD patients, chronic asthmatics and healthy controls given a high-carbohydrate meal, standardized to $40 \%$ of measured REE. The explanation for the different results may lie in the composition of the test meal. Hugli et al. (1993) carried out a similar study in eleven emphysematous patients and eleven controls given a meal consisting of $8.3 \mathrm{~kJ}(2 \mathrm{kcal})$ in the proportions (\% energy) 50 carbohydrate, 35 fat, 15 protein, giving an amount equivalent to $30 \%$ of the $24 \mathrm{~h}$ energy expenditure, and also reported no increase in DIT in the patients. The discrepancies between the various studies may be due to the way of expressing DIT, either as percentage of the total energy expenditure (which would tend to lower the value in COPD due to the relatively high REE), or as a percentage of the energy intake (which is probably more physiological). Hugli et al. (1993) found no increase whichever way DIT was expressed. The problem of interpretation of the results remains unresolved, but it seems likely that any increase in DIT, if present, must be small and cannot account for the degree of weight loss observed.

Increased activity-related thermogenesis? As mentioned previously, activity accounts for a small percentage of the total energy expenditure. Although activity is no doubt more costly to this group of patients, this is almost certainly offset by the degree of inactivity (Hugli et al. 1996).

Increased resting energy expenditure? There has been an interest in this area in recent years, as several groups have reported an increased REE in a proportion of patients with COPD. An increase in BMR of 10-20\% would be enough to account for the order of weight loss seen in COPD patients. This increase in REE in COPD again supports the notion that although a relatively reduced food intake may exacerbate malnutrition, it cannot be the primary cause, since the physiological response to starvation is for REE to fall. It is unclear whether increased REE is the cause of weight loss in COPD. There is some evidence in the literature that an increased REE in COPD is more common 
in those patients with a history of weight loss (Schols et al. 1991c). However, not all patients who are losing weight are hypermetabolic (Congleton et al. 1993) and the relationship between REE and weight loss requires further investigation. Hugli et al. (1996) found that although REE was elevated in a group of COPD patients compared with control subjects, total daily energy expenditure was identical in the two groups. This finding was ascribed to spontaneous reduction of activity in the COPD group. Possible causes of the increased REE are now considered, including:

artefact: prediction equations, body composition, measurement;

increased work of breathing;

generalized hypermetabolic state.

Increased resting energy expenditure: artefact. There are various ways of expressing REE. One of the most usual procedures is for REE to be expressed as a percentage of the expected or predicted value. The most well recognized of these procedures is the Harris-Benedict equation (Harris \& Benedict, 1919), which was produced following measurement of BMR in 187 men and 146 women in the age-range 16-74 years. The equation depends on age, height, weight and sex. Other prediction equations have since been developed, the equation of Schofield et al. (1985) being one of the more widely used. However, there are various problems with the use of all available equations. Many patients with COPD are in the older age-group and few subjects over 50 years old were studied in the original work. However, control subjects of any age generally give results within $\pm 5 \%$ of the predicted value, implying that the equation remains valid. Second, although weight is included in the prediction formula, a standard body composition is assumed and this may not be valid for COPD patients. An alternative approach is to compare REE with that of age-, sex-, heightand weight-matched controls, but the problem of possible differing body composition remains. It may be more appropriate to base metabolic rate on the amount of metabolically-active tissue, the so-called body cell mass. The best estimate of body cell mass at present is considered to be fat-free mass, and thus REE may be better expressed by adjusting for fat-free mass. There are several different methods of estimating fat-free mass, only some of which have been validated for COPD patients. Schols et al. (1991c) found that mean REE, both when expressed as a percentage of the Harris-Benedict equation value and per $\mathrm{kg}$ fat-free mass, was elevated in weight losers as compared with weight-stable patients.

It is important that REE is measured under standardized conditions, with the subject rested and in a truly stable state, otherwise erroneously high values may be obtained. Early workers used mouthpiece methods which may lead to an overestimation of REE, but the findings of a raised REE were later confirmed using a canopy and no facial apparatus (Goldstein et al. 1987; Fitting et al. 1989). The fact that similar results have been obtained by many different groups implies that REE is genuinely raised in a proportion of COPD patients.

Increased resting energy expenditure: increased work of breathing. An increase in the energy cost of breathing is often quoted as the cause of increased REE in COPD
(Wouters \& Schols, 1993). In normal subjects the contribution to the whole-body metabolic rate by the work of breathing is very small, of the order of $2-3 \%$. In COPD the respiratory muscles have a high load since they need to generate larger forces to expand the thoracic cage. They also work at a mechanical disadvantage with increasing hyperinflation. The two quantities, an increased cost of breathing at rest (which could account for the increase in REE), and an increased cost of elevated ventilation (which would not on its own account for any increase in REE, but might increase total energy expenditure), are distinct entities which are often not distinguished from each other. There is, at present, no reliable method of measuring the energy expenditure of the respiratory muscles at rest. Cherniak (1958) demonstrated that the $\mathrm{O}_{2}$ cost of breathing at various levels of ventilation could be estimated by increasing dead space. He showed that at equivalent levels of ventilation the $\mathrm{O}_{2}$ cost of breathing was far greater in an emphysematous patient compared with a normal subject, and that small increases in ventilation are associated with marked increases in $\mathrm{O}_{2}$ consumption. An important point to note is that differences in the $\mathrm{O}_{2}$ cost of augmented ventilation need not necessarily be matched by a difference in the $\mathrm{O}_{2}$ cost of breathing at rest. There is no consensus of opinion as to whether the $\mathrm{O}_{2}$ cost of breathing at rest is significantly elevated in hypermetabolic patients.

Increased resting energy expenditure: generalized hypermetabolic state. There are striking clinical similarities between the malnutrition seen in COPD and that in patients with chronic cardiac failure (cardiac cachexia), chronic liver disease and in carcinoma (cancer cachexia). Hypermetabolism is associated with all these conditions (Green et al. 1991; Morrison \& Edwards, 1991; Falconer et al. 1994). This leads to the hypothesis that there may be a common underlying systemic cause rather than the cause being specific to the respiratory system. Possible mechanisms are via thermogenic hormones (thyroxine, triiodothyronine and cortisol), endogenous catecholamines, cytokines and drug therapy. Semple et al. (1979) reported on hormonal status in sixteen males with COPD and found no evidence of thyroid abnormalities or differences between an underweight group and an overweight group. There were also no differences in mid-day cortisol levels between the two groups. Green \& Muers (1992) also found no evidence of derangement in thyroid function and found normal circulating cortisol levels in patients who were hypermetabolic. Catecholamines have been shown to increase muscle breakdown in animal studies, but they also cause a reduction in fat content and increase energy expenditure via non-shivering thermogenesis (Yang \& McElligott, 1989). There is little published work on catecholamines in COPD. The stress of increasing dyspnoea with worsening status can activate the sympathetic nervous system and release catecholamines which have a role as intermediary molecules in metabolism. Hoffard et al. (1990) found raised levels of circulating noradrenaline but not adrenaline in eleven patients with airflow obstruction and emphysema studied when in a stable clinical state. It is not known whether this finding is associated with a reduction in skeletal muscle $\beta$-receptor density and development of tolerance. REE was not measured. Hoffard et al. (1990) hypothesized that the 
raised catecholamine level was a marker of glucose need. Catecholamines reduce insulin secretion and therefore inhibit protein synthesis as amino acids are diverted to gluconeogenesis. In the Hoffard et al. (1990) study plasma amino acid levels were maintained. Tumour necrosis factor is a cytokine produced by monocytes and macrophages, it inhibits lipoprotein lipase (EC 3.1.1.34) and is pyrogenic. It triggers the release of other cytokines such as interleukins 1 and 2 which also increase energy expenditure. Tumour necrosis factor is increased in cardiac cachexia (Lavine et al. 1990), and there is recent work on tumour necrosis factor in COPD suggesting that it is elevated in a proportion of hypermetabolic patients (Schols et al. 1996). This is a difficult area to investigate because of the vast complexity of the cytokine systems and their degree of interaction with each other, the difficulty of knowing whether the measured variables are cause or effect, and also the technical difficulty of and differences in sensitivities of assay techniques. New information in this area is awaited.

The major classes of drugs used in COPD ( $\beta_{2}$ agonists, methylxanthines, quaternary ammonium compounds and oral corticosteroids) all have an effect on body tissues and metabolism. However, Schols et al. (1991c) found no association between REE and either maintenance medication or smoking in a group of eighty patients, and no other evidence has implicated drug therapy as the cause. Certain medications are difficult to assess because of their ubiquity in COPD, e.g. $\beta_{2}$ agonists, but studies so far do not implicate them in contributing to a raised REE (Congleton \& Muers, 1998).

\section{Attempts to reverse weight loss}

Refeeding. As malnourished COPD patients are not catabolic, in theory energy supplementation will lead to weight gain. Disappointingly this has been extremely difficult to achieve in practice. Controlled studies of refeeding underweight COPD patients have generally given poor results, as reviewed by Fitting (1992). A high energy intake is required to show weight gain, e.g. 1.7 times measured REE. This can be achieved in the short term with oral supplementation alone (Wilson et al. 1986). Weight gain that has been achieved has been small and not maintained after the study period is over. Any improvement in respiratory muscle strength, walking distance or other functional variables has also been small but has seemed to occur in tandem with weight gain. Once patients are no longer encouraged to continue their diets there is a spontaneous rapid reduction of intake back to pre-intervention levels and a slower fall in weight and physiological measures back to approximately pre-treatment levels (Efthimiou et al. 1988; Whittaker et al. 1990). In addition, some recent work shows that any increase in weight may be entirely due to an increase of fat mass without an increase in fat-free mass (Donahoe et al. 1994). It therefore seems likely that refeeding alone is not an effective treatment in the majority of undernourished COPD patients, and an additional or alternative approach will be necessary to give good results. Current strategies under investigation are the use of growth hormone, anabolic steroids and muscle training, in conjunction with ensuring adequate energy intake. Pape et al.
(1991) suggested that growth hormone may lead to an increase in weight and improved $\mathrm{N}$ balance in COPD. The findings were based on a pilot study and there was no control group who remained on diet alone. The anabolic effect of growth hormone probably acts via insulin-like growth factor 1 . There has been a preliminary report that insulin-like growth factor 1 is a marker of undernutrition in COPD (Sridhar et al. 1993). Schols et al. (1995) reported a benefit of the anabolic hormone nandrolene in combination with nutritional supplements and an exercise programme, when compared with nutritional supplements and exercise alone.

In summary, the cause of weight loss in COPD is not established. Energy intake obviously does not match requirements, particularly during acute exacerbations of COPD, although a decreased intake does not seem to be the prime cause. REE is increased in a proportion of COPD patients, although the aetiology of this increase and its exact relationship with weight loss is not fully understood. Weight loss in COPD is a major clinical problem which is difficult to reverse, has prognostic value and an associated morbidity. Energy requirements may be greater than predicted and attempts to compensate may be difficult for mechanical reasons. The increased REE in COPD is unique in that the patients are not hypercatabolic. The importance of knowing that a patient has an increased REE has a practical value when advising an energy intake which attempts to achieve weight gain or maintain weight. Understanding the mechanism underlying the increased REE might lead to the development of measures to manipulate it.

\section{References}

Arora NS \& Rochester DF (1982) Respiratory muscle strength and maximal voluntary ventilation in undernourished patients. American Review of Respiratory Disease 126, 5-8.

Brandstetter RD, Zakkay Y, Gutherz P \& Goldberg RJ (1988) Effect of nasogastric feeding on arterial oxygen saturation in patients with symptomatic chronic obstructive pulmonary disease. Heart and Lung 17, 170-172.

Braun SR, Dixon RM, Keim NL, Luby M, Anderegg A \& Shrago E (1984) Predictive clinical value of nutritional assessment factors in COPD. Chest 85, 353-357.

Chandra RK (1980) Cell-mediated immunity in nutritional imbalance. Federation Proceedings 39, 3088-3092.

Cherniak RM (1958) The oxygen consumption and efficency of the respiratory muscles in health and emphysema. Journal of Clinical Investigation 38, 494-499.

Congleton J (1998) Investigations into resting energy expenditure and weight loss in chronic lung disease. MD Thesis, University of Cambridge.

Congleton J, Green JH \& Muers MF (1993) Basal metabolic rate, weight loss and decline in FEV1. Monaldi Archives of Chest Disease 48, 539-540.

Congleton J \& Muers MF (1995) Relation of nutritional indices to quality of life in COPD. European Respiratory Journal 8, Suppl. 19, 172s Abstr.

Congleton J \& Muers MF (1998) Effect of regular use of high dose nebulised $\beta_{2}$ agonists on resting energy expenditure, weight, and hand grip strength in patients with chronic airflow limitation. Chest 113, 1588-1594.

Donahoe M, Mancino J, Costantino J, Lebow H \& Rogers RM (1994) The effect of an aggressive nutritional support regimen on 
body composition in patients with severe COPD and weight loss. American Journal of Respiratory and Critical Care Medicine 149, A313 Abstr.

Donahoe M, Rogers RM, Wilson DO \& Pennock BE (1989) Oxygen consumption of the respiratory muscles in normal and in malnourished patients with chronic obstructive pulmonary disease. American Review of Respiratory Disease 140, 385-391.

Driver AG, McAlevy MT \& Smith JL (1982) Nutritional assessment of patients with chronic obstructive pulmonary disease and acute respiratory failure. Chest 5, 568-571.

Efthimiou J, Flemming J, Gomes C \& Spiro SG (1988) The effect of supplementary oral nutrition in poorly nourished patients with chronic obstructive pulmonary disease. American Review of Respiratory Disease 137, 1075-1082.

Falconer J, Fearon KCH, Plester CE, Ross JA \& Carter DC (1994) Cytokines, the acute phase response and energy expenditure in weight-losing patients with pancreatic cancer. Annals of Surgery 219, 325-331.

Fitting JW (1992) Nutritional support in chronic obstructive lung disease. Thorax 47, 141-143.

Fitting JW, Frascarolo P, Jequier E \& Leuenberger P (1989) Energy expenditure and rib cage-abdominal motion in chronic obstructive pulmonary disease. European Respiratory Journal 2 , 840-845.

Gibson JNA, Morrison WL \& Halliday D (1987) Decrease in human quadriceps muscle protein turnover consequent on leg immobilisation. Clinical Science 72, 503-509.

Goldstein SA, Askanazi J, Weissman C, Thomashow BM \& Kinney JM (1987) Energy expenditure in patients with chronic obstructive pulmonary disease. Chest 91, 221-224.

Goldstein SA, Thomashow BM, Kvetan V, Askanazi J, Kinney JM \& Elwyn DH (1988) Nitrogen and energy relationships in malnourished patients with emphysema. American Review of Respiratory Disease 138, 636-644.

Gray-Donald K, Gibbons L, Shapiro SH \& Martin JG (1989) Effects of nutritional state on exercise performance in patients with chronic obsructive pulmonary disease. American Review of Respiratory Disease 140, 1544-1548.

Green JH, Bramley PN \& Lowsowsky MS (1991) Are patients with primary biliary cirrhosis hypermetabolic? A comparison between patients before and after liver transplantation and controls. Hepatology 14, 464-472.

Green JH \& Muers MF (1991) The thermic effect of food in underweight patients with emphysematous chronic obstructive pulmonary disease. European Respiratory Journal 4, 813-819.

Green JH \& Muers MF (1992) Comparisons between basal metabolic rate and diet-induced thermogenesis in different types of chronic obstructive pulmonary disease. Clinical Science $\mathbf{8 3}$, 109-116.

Harris JA \& Benedict FG (1919) A Biometric Study of Basal Metabolism in Man. Washington, DC: Carnegie Institute of Washington.

Hoffard JM, Milakofsky L, Vogel WH, Sacher RS, Savage G \& Pell S (1990) The nutritional status in advanced emphysema associated with chronic bronchitis. American Review of Respiratory Disease 141, 902-908.

Holt LE, Snyderman SE, Norton PM, Roitman E \& Finch J (1963) The plasma aminogram in kwashiorkor. Lancet ii, 1343-1348.

Hugli O, Frascaralo P, Schutz Y, Jequier E, Leuenberger P \& Fitting J (1993) Diet-induced thermogenesis in chronic obstructive pulmonary disease. American Review of Respiratory Disease 148, 1479-1483.

Hugli O, Schutz Y \& Fitting J (1996) The daily energy expenditure in stable chronic obstructive pulmonary disease. American Journal of Respiratory and Critical Care Medicine 153, 294300.
Hunter AB, Carey MA \& Larsh HW (1981) The nutritional status of patients with chronic obstructive pulmonary disease. American Review of Respiratory Disease 124, 376-381.

Jones PW, Quirk FH, Baveystock CM \& Littlejohns P (1992) A self complete measure of health status for chronic airflow limitation. American Review of Respiratory Disease 145, 1321-1327.

Knowles JB, Fairburn MS, Wiggs BJ, Chan-Yan C \& Pardy R (1988) Dietary supplementation and respiratory muscle performance in COPD. Chest 93, 977-983.

Lavine B, Kalman J, Mayer L, Fillit H \& Packer M (1990) Elevated circulating levels of tumour necrosis factor in severe chronic heart failure. New England Journal of Medicine 323, 236-241.

Lewis MI, Belman MJ \& Dorr-Uyemura L (1987) Nutritional supplementation in ambulatory patients with chronic obstructive pulmonary disease. American Review of Respiratory Disease 135, 1062-1068.

Lewis MI, Sieck GC, Fournier M \& Belman MJ (1986) Effect of nutritional deprivation on diaphragm contractility and muscle fibre size. Journal of Applied Physiology 60, 596-603.

Morrison WL \& Edwards RHT (1991) Cardiac cachexia. British Medical Journal 302, 301-302.

Morrison WL, Gibson JNA, Scrimgeour C \& Rennie MJ (1988) Muscle wasting in emphysema. Clinical Science 75, 415-420.

Pape GS, Friedman M, Underwood LE \& Clemmons DR (1991) The effect of growth hormone on weight gain and pulmonary function in patients with chronic obstructive lung disease. Chest 99, 1495-1500.

Pugh LGCE (1962) Physiological and medical aspects of the Himalayan Scientific and Mountaineering Expedition 19601961. British Medical Journal ii, 621-627.

Rennie MJ, Babij P, Sutton JR, Tonkins WJ, Read WW, Ford C \& Halliday D (1983) Effects of acute hypoxia on forearm leucine metabolism. In Hypoxia, Exercise and Altitude: Proceedings of the Third Banff International Hypoxia Symposium, pp. 317-323. New York: Alan R. Liss.

Sargeant AJ, Davies CTM, Edwards RHT, Maunder C \& Young A (1977) Functional and structural changes after disuse of human muscle. Clinical Science and Molecular Medicine 52, 337-342.

Schols AMWJ, Buurman WA, Staal-van den Brekel AJ, Dentener MA \& Wouters EFM (1996) Evidence for a relation between metabolic derangements and increased levels of inflammatory mediators in a subgroup of patients with chronic obstructive pulmonary disease. Thorax 51, 819-824.

Schols AMWJ, Mostert R, Soeters PB \& Wouters EFM (1991a) Body composition and exercise performance in patients with chronic obstructive pulmonary disease. Thorax 46, 695-699.

Schols AMWJ, Soeters P, Dingemans AMC, Mostert R, Frantzen PJ \& Wouters EFM (1993) Prevalence and characteristics of nutritional depletion in patients with stable COPD eligible for pulmonary rehabilitation. American Review of Respiratory Disease 147, 1151-1156.

Schols AMWJ, Soeters PB, Mostert R, Pluymers RJ \& Wouters EFM (1995) Physiologic effects of nutritional support and anabolic steroids in patients with chronic obstructive pulmonary disease. American Journal of Respiratory and Critical Care Medicine 152, 1268-1274.

Schols AMWJ, Soeters PB, Mostert R \& Wouters EFM (1991b) Energy balance in chronic obstructive pulmonary disease. American Review of Respiratory Disease 143, 1248-1252.

Schols AMWJ, Soeters PB, Mostert R \& Wouters EFM (1991c) Energy balance in chronic obstructive pulmonary disease. American Review of Respiratory Disease 143, 1248-1252.

Semple PD, Watson WS, Beastall GH, Bethel MIF, Grant JK \& Hume R (1979) Diet, absorption, and hormone studies in relation to body weight in obstructive airways disease. Thorax 34, 783788 . 
Sridhar MK, Lean MJ, Beastall G \& Banham SW (1993) Insulin like growth factor- 1 as a marker of malnutrition in patients with emphysematous chronic obstructive pulmonary disease (COPD). European Respiratory Journal 6, Suppl. 17, 427s Abstr.

Sukumalchantra Y \& Williams H (1965) Serial studies of pulmonary function in patients with chronic obstructive pulmonary disease. American Journal of Medicine 39, 941-945.

Thurlbeck WM (1978) Diaphragm and body weight in emphysema. Thorax 33, 483-487.

Vandenbergh E, VandeWoestijne K \& Gyselen A (1967) Weight changes on the terminal stages of COPD. American Review of Respiratory Disease 95, 556-566.

Whittaker JS, Ryan CF, Buckley PA \& Road JD (1990) The effects of refeeding on peripheral and respiratory muscle function in malnourished chronic obstructive pulmonary disease patients. American Review of Respiratory Disease 142, 283-288.
Wilson DO, Rogers RM \& Hoffman RM (1985) Nutrition and chronic lung disease. American Review of Respiratory Disease 132, 1347-1365.

Wilson DO, Rogers RM, Sanders MH, Pennock BE \& Reilly JJ (1986) Nutritional intervention in malnourished patients with emphysema. American Review of Respiratory Disease 134, 672677.

Wilson DO, Rogers RM, Wright EC \& Anthonisen NR (1989) Body weight in chronic obstructive pulmonary disease. American Review of Respiratory Disease 139, 1435-1438.

Wouters EFM \& Schols A (1993) Prevalence and pathophysiology of nutritional depletion in chronic obstructive pulmonary disease. Repiratory Medicine 87, Suppl. B, 45-47.

Yang YT \& McElligott MA (1989) Multiple actions of $\beta$ adrenergic agonists on skeletal muscle and adipose tissue. Biochemical Journal 261, 1-10.

(C) Nutrition Society 1999 